\title{
Anti-Inflammatory Activity of Crude Venom Isolated from Parasitoid Wasp, Bracon hebetor Say
}

\author{
Evelyn Saba, ${ }^{1}$ Tahir Shafeeq, ${ }^{2}$ Muhammad Irfan, ${ }^{1}$ Yuan Yee Lee, ${ }^{1}$ Hyuk-Woo Kwon, ${ }^{1}$ \\ Myung Gi Seo, ${ }^{3}$ Sang-Joon Park, ${ }^{3}$ Kyeong-Yeoll Lee, ${ }^{2}$ and Man Hee Rhee ${ }^{1}$ \\ ${ }^{1}$ Laboratory of Veterinary Physiology and Cell Signaling, College of Veterinary Medicine, Kyungpook National University, Daegu, \\ Republic of Korea \\ ${ }^{2}$ Division of Applied Biosciences, College of Agriculture and Life Sciences, Kyungpook National University, Daegu, Republic of Korea \\ ${ }^{3}$ Laboratory of Veterinary Histology, College of Veterinary Medicine, Kyungpook National University, Daegu, Republic of Korea
}

Correspondence should be addressed to Man Hee Rhee; rheemh@knu.ac.kr

Received 17 May 2017; Revised 26 July 2017; Accepted 29 August 2017; Published 29 October 2017

Academic Editor: Mirella Giovarelli

Copyright (c) 2017 Evelyn Saba et al. This is an open access article distributed under the Creative Commons Attribution License, which permits unrestricted use, distribution, and reproduction in any medium, provided the original work is properly cited.

Pest control in the agricultural fields, a major concern globally, is currently achieved through chemical or biological methods. Chemical methods, which leave toxic residue in the produce, are less preferred than biological methods. Venoms injected by stings of various wasps that kill the pest is considered as the examples of the biological method. Although several studies have investigated the biological control of pests through these venoms, very few studies have reported the effects of these venoms on mammalian cells. Bracon hebetor, an ectoparasitoid of the order Hymenoptera, is having a paramount importance in parasitizing various lepidopterous larvae including Plodia interpunctella also called as Indianmeal moth (IMM). Since it is biologically controlled by $B$. hebetor venom, therefore in our study, herein for the first time, we report the anti-inflammatory activities of the venom from $B$. hebetor (BHV). We developed a septic shock mice model for in vivo anti-inflammatory studies and RAW 264.7 cells for in vitro studies. Our results clearly demonstrate that BHV can dose dependently abrogate the nitric oxide (NO) production and suppress the levels of proinflammatory mediators and cytokines without posing any cytotoxicity via the nuclear factor kappa B (NF- $\kappa \mathrm{B})$ and mitogen-activated protein kinase (MAPK) pathways.

\section{Introduction}

Parasitoids constitute a powerful weapon for the biological control of lepidopteran insects owing to their venomous and paralyzing stings. One of such parasitoids Bracon hebetor Say $(\mathrm{HB})$, occupies a prime place for its parasitic relationship with Plodia interpunctella or the Indianmeal moth (IMM). IMM is a widely distributed destructive pest of agricultural produce, which attacks on the final processed product causing huge economic losses to the manufacturers. While many studies in the past have reported various chemical and alternate chemical-based methods to counteract this pest population, the toxic residue left behind by these methods cannot be ignored. B. hebetor biologically controls IMM by paralyzing it and causing its death. The chemical nature of BHV which is injected into the host has already been studied in detail. While any kind of venom usually consists of a cocktail of proteins that disrupt the homeostasis of the host, but some venoms such as bee venom are also considered to be a panacea for human ailments [1]. The host-parasite relationship of $P$. interpunctella and B. hebetor has been studied extensively in the past, yet no study until now has highlighted the venom's effects in any other context [2-4]. The current study on the BHV was therefore conceptualized based on the already established effects of honey bee venom on mammalian ailments including inflammation and cancer and also its application in human cosmetic industry [5-7].

An invasion of a foreign substance in the body is counteracted by the natural defensive mechanism called "inflammation." Inflammation is a phenomenon that orchestrates various chemicals in the cells to counteract with the 
invading material. While inflammation is going on inside the body, it manifests itself externally via signs like swelling, edema, redness, pain, and skin reddening [8]. However, inside the cell, there is production of nitric oxide (NO) that is released under the action of nitric oxide synthase (NOS) enzyme when L-arginine is converted to L-citrulline. Subsequently, a cascade of proinflammatory mediators and cytokines is released that serves to flare up inflammatory process in regard to clear up the foreign antigen. This includes cyclooxygenase-2 (COX-2), interleukins, that is, IL- $1 \beta$ and IL- 6 , and tissue necrosis factor- $\alpha$ (TNF- $\alpha$ ) that attract other inflammatory chemokines as well as to help up for clearance. All these proinflammatory mediators and cytokines lead to activation of classical inflammatory pathway, that is, NF- $\kappa \mathrm{B}$ and MAPK pathways $[9,10]$. Activation of these pathways regulates a systematic inflammatory response in order to neutralize the invading particle. While inflammation is a natural defense mechanism of the body towards foreign invasion, uncontrolled and generalized inflammatory responses have devastating consequences for the body. Therefore, timely control of inflammation either by the body itself or by an exogenous agent is required.

For this purpose in our study, we tried to unravel the anti-inflammatory activities of BHV on RAW 264.7 cells and in mice model of septic shock. Our results have demonstrated that BHV dose dependently suppressed the nitric oxide (NO) production without any cytotoxicity with suppression in the expression levels of proinflammatory cytokines and mediators both transcriptionally and translationally. Furthermore, it suppresses these effects through the classical NF- $\kappa \mathrm{B}$ pathway and mitogen-activated protein kinase (MAPK).

\section{Methods}

2.1. Chemicals and Reagents. Dulbecco's Modified Eagle's medium (DMEM) (Daegu, Korea), fetal bovine serum (FBS) (Welgene Co., Daejeon, Korea), streptomycin and penicillin (Lonza, MD, USA), TRIzol ${ }^{\circledR}$ reagent (Invitrogen, Carlsbad, CA, USA), oligo dT (Bioneer Co., Daejeon, Korea), and primers for iNOS, COX-2, TNF- $\alpha$, IL-6, and IL- $1 \beta$ were purchased from Bioneer. Lipopolysaccharide (LPS) (Escherichia coli 055:B5) and 3-(4,5-dimethylthiazol-2-yl)-2,5-diphenyltetrazoliumbromide (MTT) were procured from SigmaAldrich (St. Louis, MO, USA). Specific antibodies against the phospho- and/or total form of IRAK1, TAK1, IKK $\alpha / \beta$, $\mathrm{I} \kappa \mathrm{B}, \mathrm{NF}-\kappa \mathrm{B}$ p 65 , iNOS, COX-2, $\beta$-actin, and anti-rabbit horse peroxidase-linked secondary antibody were obtained from Cell Signaling Technology (Danvers, MA, USA). All other reagents and chemicals used were obtained from Sigma-Aldrich.

2.2. Procurement of Crude Venom Extract from B. hebetor Female Wasps. The procurement, purification, and characterization of the venom were according to Quistad et al. and Moreau and Asgari $[11,12]$. Briefly, B. hebetor were specifically reared and selected from laboratory culture and immobilized on ice for few minutes. The venom glands from each female wasp were then dissected under a microscope and transferred to double-distilled water (DDW). At a single time, batches of 10 glands were dissected and transferred to $50 \mu \mathrm{L}$ of DDW, homogenized manually, and centrifuged at $12,000 \mathrm{rpm}$ for $5 \mathrm{~min}$ at $4^{\circ} \mathrm{C}$. The supernatant containing the crude venom was then stored at $-20^{\circ} \mathrm{C}$ for future experimental use. Venom proteins for the experimental use were quantified according to Bradford assay.

2.3. Ethical Statement. All animal care and experimental procedures were carried out in strict accordance with internationally accepted guidelines on the use of laboratory animals (IACUC) and the protocols were approved by the Animal Care Committee of the College of Veterinary Medicine, Kyungpook National University, Daegu, South Korea (permit number: 2017-36). For acute LPS treatment, we monitored mice for 96 hours for total and every 12 hours for mortality. After $96 \mathrm{hr}$, all the remaining mice from the survival study were euthanized with excessive $\mathrm{CO}_{2}$ inhalation. For chronic LPS study, we monitored mice for $24 \mathrm{hr}$ total and 12 hours generally for any mortality or other pathology. Our all experimental time was estimated to be around 2 weeks including acclimatization.

2.4. Animal Experiments. Male ICR mice 6-8 weeks old (26-29g) were purchased from Charles River, Orient Biotechnology, Gyeonggi-do, South Korea. The mice were housed in a specific pathogen-free barrier facility at $21 \pm 2{ }^{\circ} \mathrm{C}$ with a relative humidity of $60 \pm 10 \%$ under a $12 \mathrm{hr}$ light and dark cycle. Feed and water were provided ad libitum. The mice were divided into 3 groups with each group $(n=10)$ for survival study with $30 \mathrm{mg} / \mathrm{kg}$ LPS and $(n=6)$ for clinical studies with LPS $20 \mathrm{mg} / \mathrm{kg}$. For survival and clinical studies, venom was given i.p. every day for 5 days prior to LPS treatment. The grouping was group 1: basal (vehicle treatment), group 2: LPS (30 mg/kg or $20 \mathrm{mg} / \mathrm{kg}$ ), group 3: (venom $30 \mu \mathrm{g} / \mathrm{kg}+\mathrm{LPS})$.

2.5. Cell Culture. Murine macrophage cell line RAW 264.7, originating from American Type Culture Collection (ATCC, TIB-71), was cultured in Dulbecco's Modified Eagle Medium (DMEM) supplemented with 5\% fetal bovine serum (FBS) (Welgene Co., Daejeon) and $100 \mathrm{IU} / \mathrm{mL}$ penicillin and $100 \mu \mathrm{g} / \mathrm{mL}$ streptomycin sulfate (Lonza, MD, USA) with the incubating conditions of humidified $5 \% \mathrm{CO}_{2}$ incubator at $37^{\circ} \mathrm{C}$. The cell line was directly obtained from the company.

2.6. Nitric Oxide (NO) Measurement. Griess reaction was the principle for measuring nitric oxide (NO) production. In short, RAW 264.7 cells were seeded in 96-well plates at the density of $2 \times 10^{4}$ cells/well and incubated with or without LPS $(0.1 \mu \mathrm{g} / \mathrm{mL})$ in absence or presence of BHV $(0.1-0.4 \mu \mathrm{g} / \mathrm{mL})$ for $18 \mathrm{hr}$. The cell culture supernatants $(100 \mu \mathrm{L})$ were then mixed with Griess reagent $(0.2 \%$ naphthylethylenediamine dihydrochloride and $2 \%$ sulphanilamide in 5\% phosphoric acid) in double-distilled water (DDW) at equal volumes and incubated for $5 \mathrm{~min}$ at RT $\left(25^{\circ} \mathrm{C}\right)$. The absorbance in each well was then analyzed at $540 \mathrm{~nm}$ in a microplate reader (VersaMax, Molecular Devices, LLC, CA, USA). 
2.7. Cell Viability (MTT) Assay. Cytotoxic effects of BHV were studied by measuring the cell viability via MTT assay. Briefly, MTT reagent, that is, 3-(4,5-dimethylthiazol-2-yl)2,5-diphenyltetrazolium bromide was added to culture medium in 96-well plates at a final concentration of $0.1 \mathrm{mg} / \mathrm{mL}$. After $4 \mathrm{hr}$ of incubation at $37^{\circ} \mathrm{C}$ in $5 \% \mathrm{CO}_{2}$, the violet-colored crystals were homogenized in dimethyl sulfoxide (DMSO) $100 \mu \mathrm{L} /$ well and absorbance was measured at $560 \mathrm{~nm}$.

2.8. RNA Extraction and $q R T-P C R$. For transcriptional studies, RAW 264.7 cells were pretreated with BHV at given concentrations for $30 \mathrm{~min}$ and then stimulated with LPS $(0.1 \mu \mathrm{g} / \mathrm{mL})$ for $18 \mathrm{hr}$. TRIzol reagent was harvested for total RNA extraction both from cells and tissues (Invitrogen, Carlsbad, CA, USA) following the manufacturer's instructions. Subsequent steps were carried out as previously described [13]. Quantitative sequence of primers used for PCR is given in Table 1.

2.9. Western Blot Analysis. For direct evidence of signaling pathways followed by BHV, RAW264.7 cells were treated with BHV $(0.1-0.4 \mu \mathrm{g} / \mathrm{mL})$ in the presence and absence of LPS $(0.1 \mu \mathrm{g} / \mathrm{mL})$. NE-PER ${ }^{\circledR}$ Nuclear and Cytoplasmic Extraction Reagents (Thermo Fisher Scientific Co., LTD, Korea) was used for separation of nuclear and cytosolic fractions from cells and tissues. Preceding steps were according to Saba et al. [14].

2.10. TNF $\alpha, N O$, and MDA Assay. The plasma was harvested from septic shock mice after euthanasia and then was subjected to different commercially available kits, that is, TNF- $\alpha$ ELISA (R\&D systems), NO, and MDA (Abcam), according to the manufacturer's instructions.

2.11. Hematoxylin and Eosin (HÆE) Staining. The lungs and testis tissue after euthanasia to mice were collected in $10 \%$ neutral buffered formalin, and then tissues were processed for basic H\&E staining according to established protocols [15].

2.12. Transient Transfection and Luciferase Assay. Luciferase activity in HEK 293T cells (ATCC, CRL 1573) was measured via the calcium-phosphate method. Briefly, cells were seeded in $60 \mathrm{~mm}$ at a density of $5 \times 10^{5}$ cells/plate and incubated for $24 \mathrm{hr}$ and then transfected with TK Renilla (pRL-TK) and $\mathrm{NF}-\kappa \mathrm{B}$ firefly luciferase ( $\mathrm{pNF}-\kappa \mathrm{BLuc}$ ) constructs. The transfected medium was replaced with the normal FBS supplemented media after $6 \mathrm{hr}$ and then again incubated for $18 \mathrm{hr}$. The next day, cells were seeded in 24-well plates at the density of $5 \times 10^{4}$ cells/well and incubated again overnight. They were then pretreated with BHV $(0.1-0.4 \mu \mathrm{g} / \mathrm{mL})$ for $30 \mathrm{~min}$ before PMA stimulation for $6 \mathrm{hr}$. The following day, cells were quantified for luciferase activity using Promega's Dual-Glo luciferase assay kit (Promega Corporation, WI, USA) according to the manufacturer's instructions. GloMax Luminometer (Promega) was used for measuring luciferase activity. Luciferase activity was normalized to TK Renilla activity. Transcriptional activity of AP1 was also studied similarly.
TABLE 1: Sequence of primers used for RT-PCR for B. hebetor venom gene expression.

\begin{tabular}{|c|c|c|}
\hline Gene & Primer & Oligonucleotide sequence $\left(5^{\prime}-3^{\prime}\right)$ \\
\hline \multirow{2}{*}{ GAPDH } & $\mathrm{F}$ & $5^{\prime}$ CAATGAATACGGCTACAGCAAC $3^{\prime}$ \\
\hline & $\mathrm{R}$ & 5'AGGGAGATGCTCAGTGTTGG3' \\
\hline \multirow{2}{*}{ iNOS } & $\mathrm{F}$ & $5^{\prime}$ CCCTTCCGAAGTTTCTGGCAGCAGC3' \\
\hline & $\mathrm{R}$ & 5'GGCTGTCAGAGCCTCGTGGCTTTGG3' \\
\hline \multirow{2}{*}{ COX-2 } & F & $5^{\prime}$-TCTCAGCACCCACCCGCTCA-3' \\
\hline & $\mathrm{R}$ & 5'-GCCCCGTAGACCCTGCTCGA-3' \\
\hline \multirow{2}{*}{ IL- $1 \beta$} & $\mathrm{F}$ & 5'CAGGGTGGGTGTGCCGTCTTTC3' \\
\hline & $\mathrm{R}$ & 5'TGCTTCCAAACCTTTGACCTGGGC3' \\
\hline \multirow{2}{*}{ TNF- $\alpha$} & $\mathrm{F}$ & 5'TTGACCTCAGCGCTGAGTTG3' \\
\hline & $\mathrm{R}$ & 5'CCTGTAGCCCACGTCGTAGC3' \\
\hline \multirow{2}{*}{ IL-6 } & $\mathrm{F}$ & $5^{\prime}$-GTACTCCAGAAGACCAGAGG-3' \\
\hline & $\mathrm{R}$ & $5^{\prime}$-TGCTGGTGACAACCACGGCC-3' \\
\hline
\end{tabular}

2.13. Statistical Analysis. Data was statistically analyzed using one-way analysis of variance (ANOVA) and Dunnett's test. Values are presented as mean \pm SEM. ${ }^{* *} p<0.05$ and ${ }^{* * *} p<0.001$ were considered statistically significant.

\section{Results}

3.1. LPS-Induced Inflammation Was Suppressed by B. hebetor Venom. The component of the gram-negative bacteria's cell wall that is a universal inflammatory inducer is the lipopolysaccharides (LPS) [16]. Therefore, they are used in both in vitro and in vivo studies as inflammation-inducing agents. Hence, in our study, we investigated whether BHV affects LPS-induced NO production in RAW 264.7 cells and septic shock mice model. As can be seen in Figure 1(a), BHV potently suppressed the LPS-induced inflammation without showing any cytotoxic effect for concentration range used in this study (Figure 1(b)). Moreover, in the plasma of mice given chronic dose of LPS, NO was suppressed (Figure 1(c)) and the venom-treated group showed excellent survival rate of $100 \%$ in mice given with a lethal dose of LPS (Figure $1(\mathrm{~d})$ ).

3.2. B. hebetor Venom Inhibited the Expression of Proinflammatory Mediators. Proinflammatory mediators are the components in the cell that flares up or mediate inflammation. The two most common and rapidly expressing proinflammatory mediators are iNOS and COX-2. We therefore analyzed BHV's effects on proinflammatory mediators' expression. As evidenced by Figures 2(a), 2(b), 2(c), and 2(d), BHV inhibited both the transcriptional and translational expression levels of these components as clearly shown by PCR and immunoblot analysis in both cells and lung and testis tissue of mice which were given chronic LPS dose.

3.3. Diminution of Proinflammatory Cytokines B. hebetor Venom. Proinflammatory cytokines are the chemicals that are released in response to inflammation induced as a result of a foreign invader. They serve to increase the magnitude 


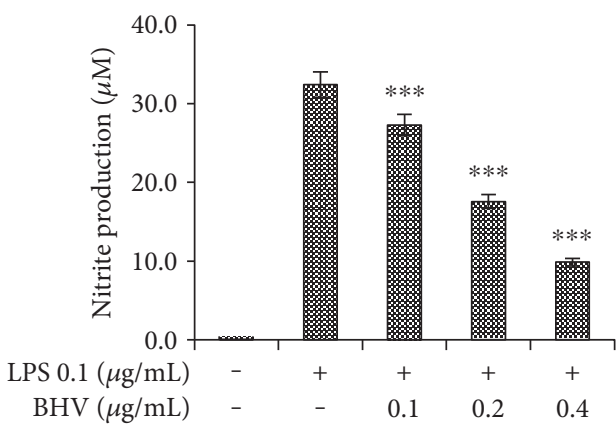

(a)

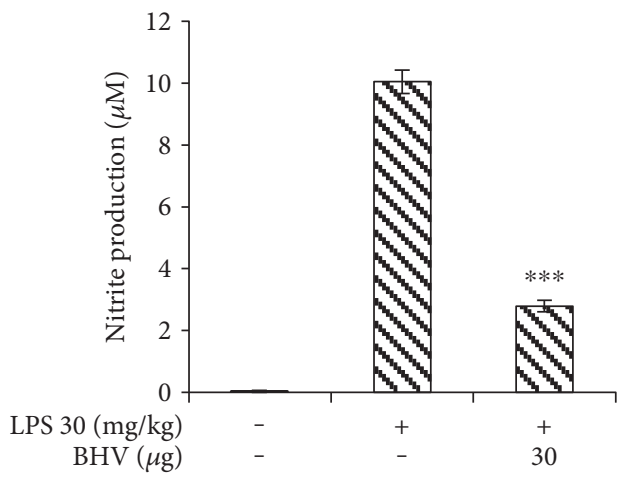

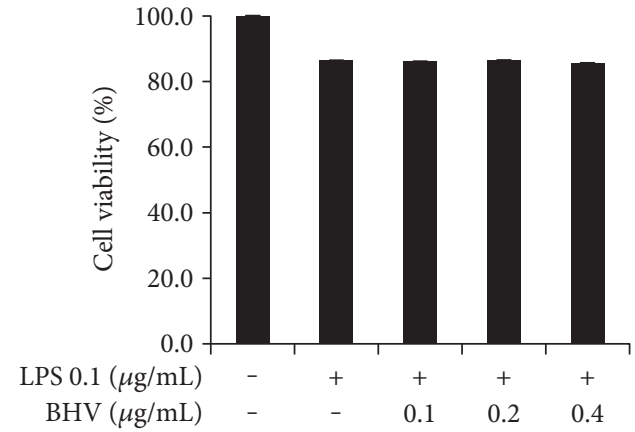

(b)

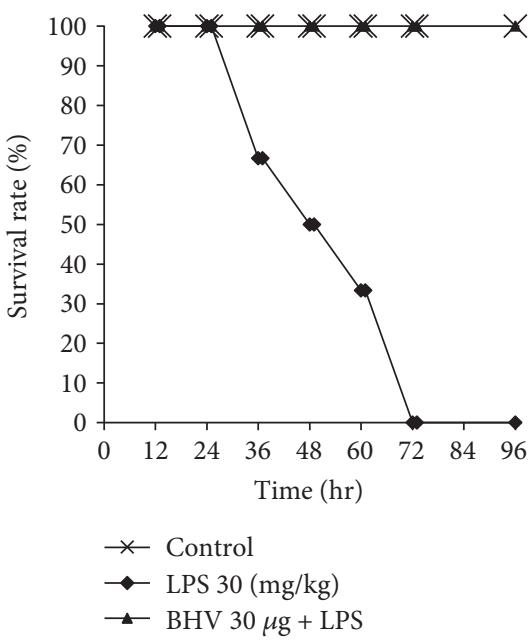

(d)

FIGURE 1: B. hebetor venom suppressed LPS-mediated NO release without any cytotoxicity. RAW 264.7 cells were seeded in 96-well plates for $18 \mathrm{hr}$ and then preincubated with BHV $(0.1 \mu \mathrm{g} / \mathrm{mL}-0.4 \mu \mathrm{g} / \mathrm{mL})$ for $30 \mathrm{~min}$ and then stimulated with LPS $(0.1 \mu \mathrm{g} / \mathrm{mL})$ for $18 \mathrm{hr}$. The cell supernatant was transferred to a 96-well plate and reacted with equal amounts of Griess reagent, and then NO production was measured at $540 \mathrm{~nm}$ (a). Effects of BHV on cell viability were measured by MTT assay and absorbance was measured at $560 \mathrm{~nm}$ (b). NO production was also observed in mice chronically treated with LPS (c). For survival rate, mice were given LPS injection with a lethal dose of $30 \mu \mathrm{g} / \mathrm{kg}$ and monitored for 96 hours (d). Values in bar graph are mean \pm SEM of at least 3 independent experiments. ${ }^{* * *} p<0.001$ compared to LPS only.

of inflammation and if uncontrolled can lead to severe septic shock. Figures 3(a), 3(b), and 3(c) clearly shows that BHV diminished the mRNA expression levels of IL- $1 \beta$, IL- 6 , and TNF- $\alpha$ in a sharp dose-dependent manner in both cells and tissues. Furthermore, we analyzed the TNF- $\alpha$ and MDA levels in the serum of septic shock mice model and found that they both were strongly inhibited in the BHV-treated group (Figures 4(a) and 4(b)). We also geared to check the histology of lungs and testis tissue which is more prone to LPS shock. Figure 4(c) shows the normal histology of the lungs with clear alveolar spaces and no infiltration of inflammatory cells. However, Figure 4(d) shows the septic shock prone mice with almost no alveolar space that is filled with inflammatory cells. But this histology is reverted back to almost normal by venom treatment as shown in Figure 4(e). In case of the testis tissue, Figure 4(f) shows the normal histology of the testis with proper alignment of cells and subsequent formation of spermatozoa in the seminiferous tubules. In Figure 4(g), however, the seminiferous tubules are degenerated because of LPS shock. But with venom treatment, they appear to regain their normal morphology (Figure 4(h)).
3.4. NF- $\kappa B$ and MAPK Pathways Are the Major Players in B. hebetor Venom Anti-Inflammatory Activity. NF- $\kappa \mathrm{B}$ pathway is the universal cascade of transcriptional factors that is followed by any substance for eliciting its antiinflammatory properties. It is activated when toll-like receptor 4 activation (TLR-4) binds with LPS thus causing the downstream activation of events [17]. Figure 5(a) depicts how BHV has diminished the phosphorylation of interleukin receptor-associated kinase 1 (IRAK1) and transforming growth factor beta-activated kinase 1 (P-TAK-1) which are the foremost initiating factors for NF- $\kappa \mathrm{B}$ pathway. Then preceding downwards, BHV has suppressed the phosphorylation of IKK $\alpha / \beta$ that degraded $\mathrm{I} \kappa \mathrm{B} / \alpha$. I $\kappa \mathrm{B} / \alpha$ then sets NF- $\kappa \mathrm{B}$ free from its adjacent subunits and translocates to the nucleus where its phosphorylation had been strongly inhibited by $\mathrm{BHV}$. Moreover, in the lung and testis tissues, NF- $\kappa \mathrm{B}$ is also shown to be strongly inhibited with venom treatment (Figure 5(b)). MAPK pathway is also a very commonly activated inflammatory pathway in times of stress to cells. This consists of extracellular signal regulating kinase (ERK), cJun N-terminal kinases (JNK), and p38. These factors 


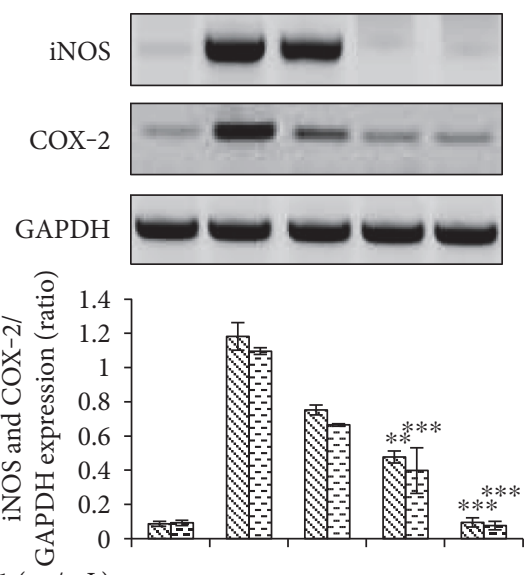

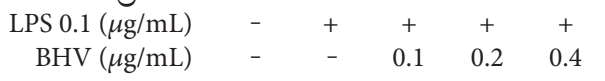

S COX-2

E- iNOS

(a)
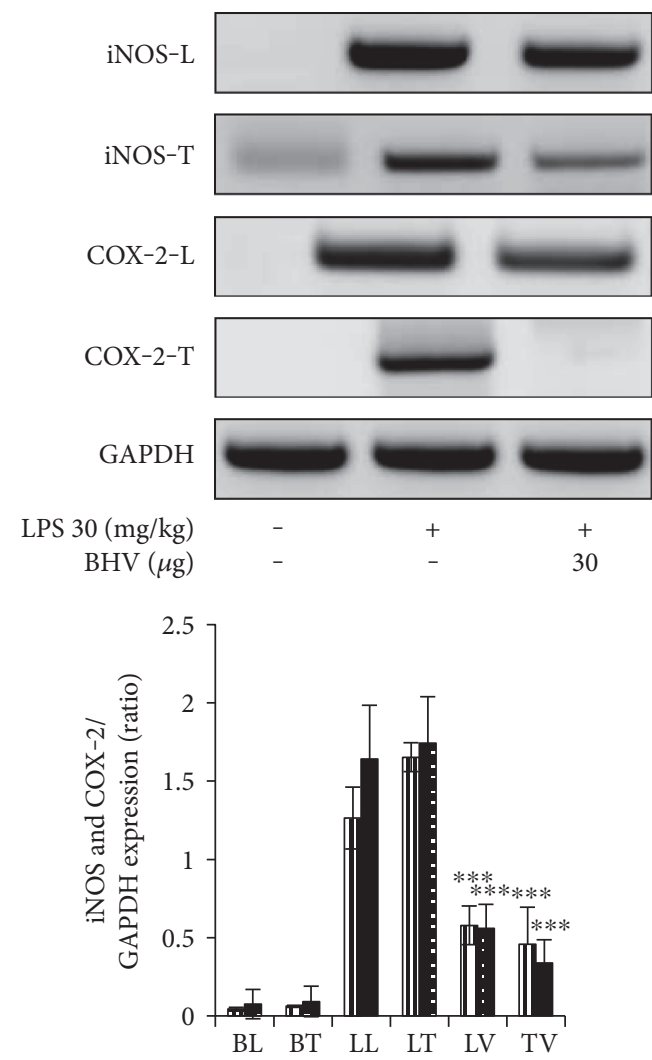

DiNOS

COX-2

(c)

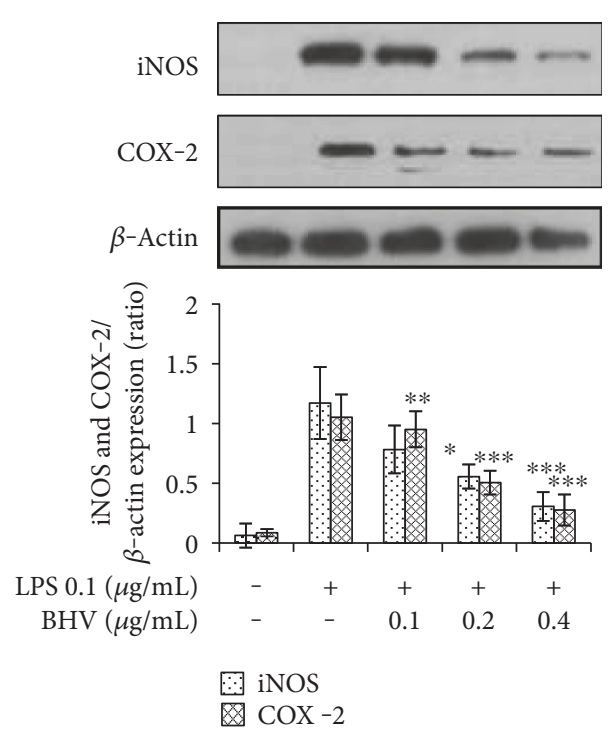

(b)
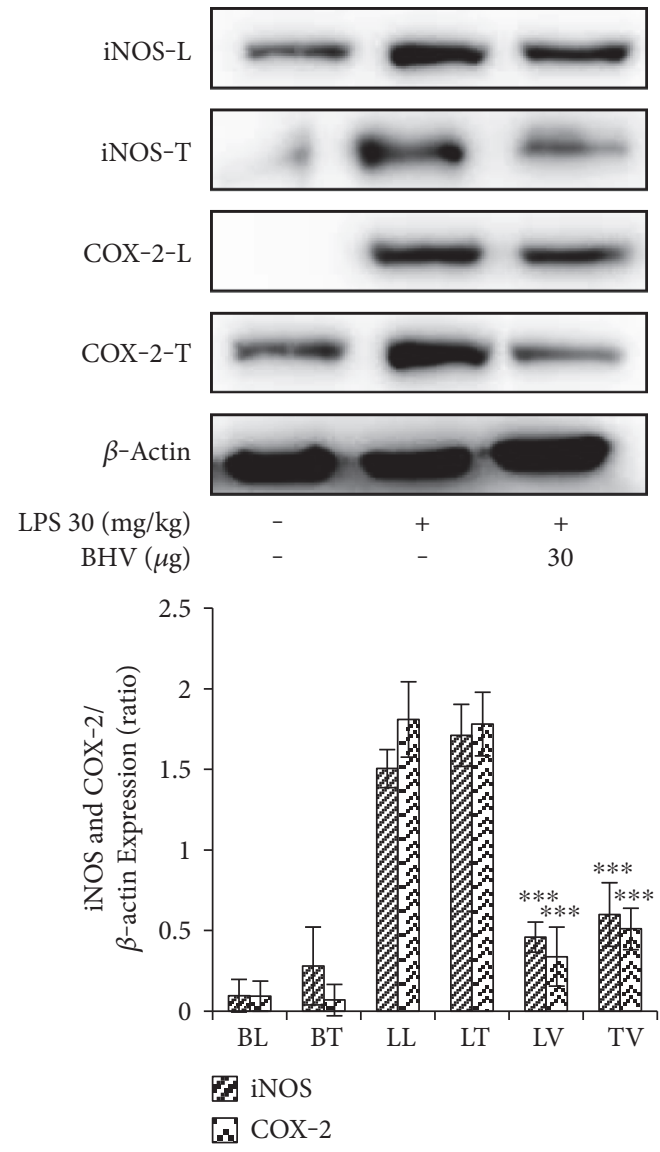

(d)

FIGURE 2: Inhibitory effects of $B$. hebetor venom on the expression of iNOS and COX-2. For mRNA and protein expressions, RAW 264.7 cells were seeded in 6-well plates and treated with indicated concentrations of BHV $(0.1 \mu \mathrm{g} / \mathrm{mL}-0.4 \mu \mathrm{g} / \mathrm{mL})$ for 30 min and then stimulated with LPS $(0.1 \mu \mathrm{g} / \mathrm{mL})$ for $18 \mathrm{hr}$. Total RNA from cell, lung, and testis tissues and total protein was extracted using their respective kit protocols. PCR product was analyzed on agarose gels with GAPDH as the internal control. Protein quantitation was done by Pro-Measure (iNtRON biotechnology, Daejeon, Korea), and then proteins were run on SDS-PAGE and analyzed by ECL chemiluminisence with $\beta$-actin as internal control. PCR and protein expression in RAW 264.7 cells (a-b). PCR and protein expression in lungs and testis tissue (c-d). Western blot and PCR images are representative of 3 independent experiments. Bar values of ${ }^{*} p<0.01,{ }^{* *} p<0.005$, and ${ }^{* * *} p<0.001$ were considered statistically significant. $\mathrm{BL}=$ basal lung; $\mathrm{BT}=$ basal testis; $\mathrm{LL}=\mathrm{LPS}$ lung; $\mathrm{LT}=\mathrm{LPS}$ testis; $\mathrm{LV}=$ lung venom; TV= testis venom. 


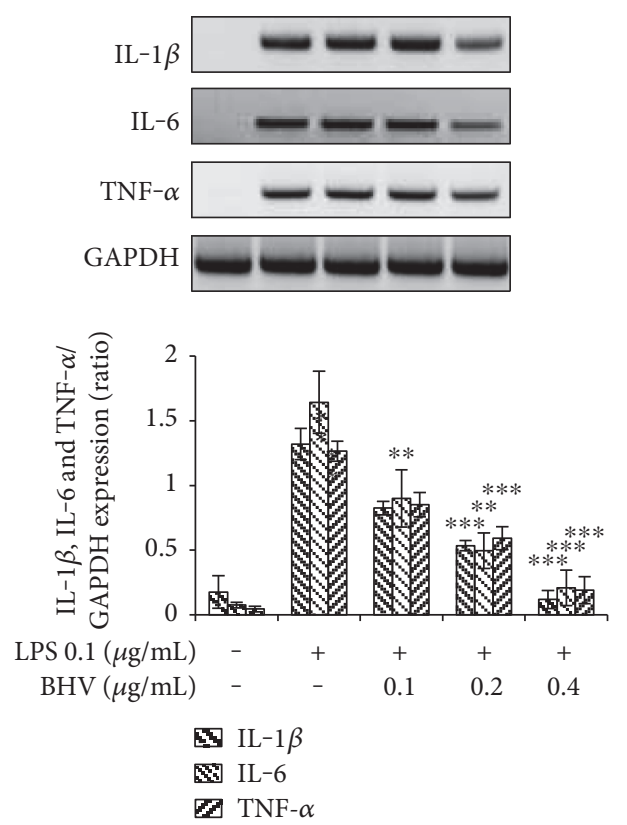

(a)

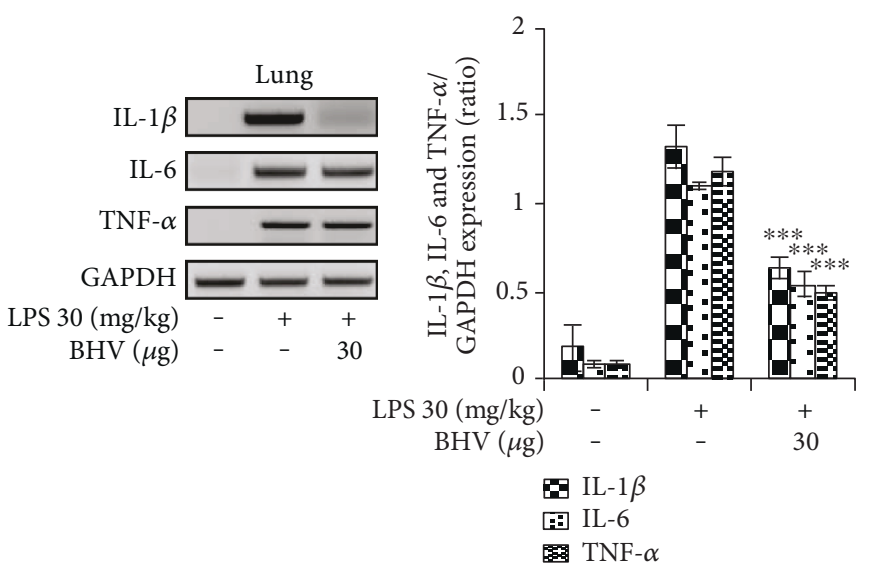

(b)
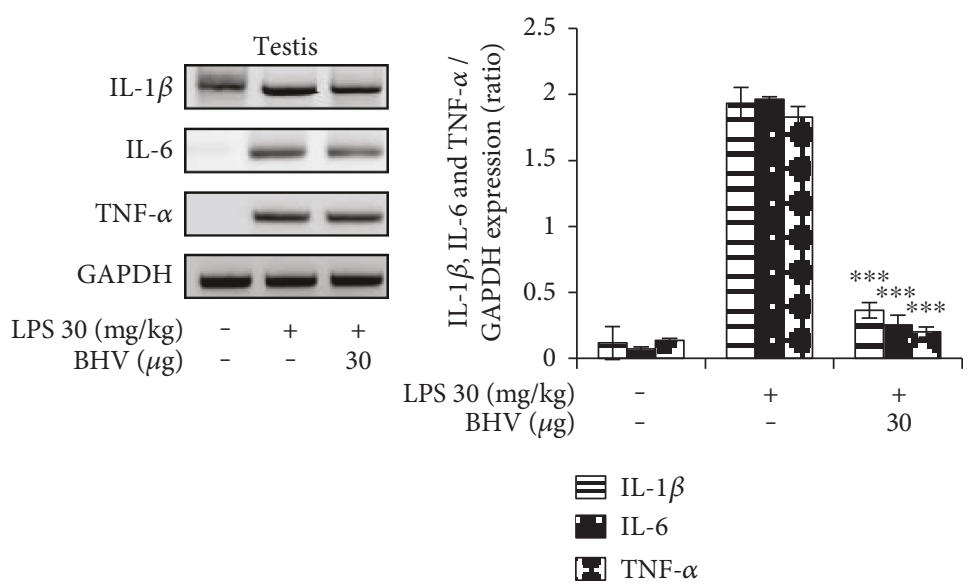

(c)

FiguRE 3: $B$. hebetor venom diminished mRNA expressions of IL-1 $\beta$, IL-6, and TNF- $\alpha$ under LPS stimulation. For mRNA expression, RAW 264.7 cells were pretreated with BHV $(0.1 \mu \mathrm{g} / \mathrm{mL}-0.4 \mu \mathrm{g} / \mathrm{mL})$ for $30 \mathrm{~min}$ and then stimulated with LPS $(0.1 \mu \mathrm{g} / \mathrm{mL})$ for $18 \mathrm{hr}$. Total RNA from cell, lung, and testis tissue was isolated by TRIzol RNA extraction reagent, and mRNA expression of IL-1 $\beta$, IL-6, and TNF- $\alpha$ was determined by RT-PCR. GAPDH was used as the housekeeping gene. Images are representative of 3 independent experiments. Cytokines expression in cells (a). Cytokines expression in lungs (b). Cytokines expression in testis (c). Values in bar graph are mean \pm SEM of 4 independent experiments. ${ }^{* * *} p<0.001$ and ${ }^{* *} p<0.005$ compared to LPS only.

contribute to the elevation in the expression of activator protein 1 (AP-1) in the nucleus that regulates the production of various genes related to inflammation and immunity [10]. Our results have shown that BHV had dose dependently inhibited the phosphorylation levels of these all three basic components in the MAPK pathway indicating that not only NF- $\kappa \mathrm{B}$ but also MAPK is affected by these venom proteins (Figure 5(c)).

3.5. Abrogation of Transcriptional Activity of NF- $\kappa B$ and $A P-1$ by $B$. hebetor Venom. To conclusively establish the direct evidence for $B$. hebetor venom signal transduction via NF- $\kappa$ B and MAPK pathway, we transfected their respective plasmids in the HEK 293T cells and found the expression binding levels via luciferase assay. As shown in Figure 6, BHV had dose dependently diminished the expression levels of both NF- $\kappa \mathrm{B}$ and AP-1 (which is the activating transcriptional factor of MAPK in the nucleus) strengthening the possibility that indeed the BHV venom mediated its potent anti-inflammatory effects via the NF- $\kappa \mathrm{B}$ and MAPK pathways.

\section{Discussion}

The mechanism through which parasitoids serve in the biological control for decreasing agricultural pests is via 


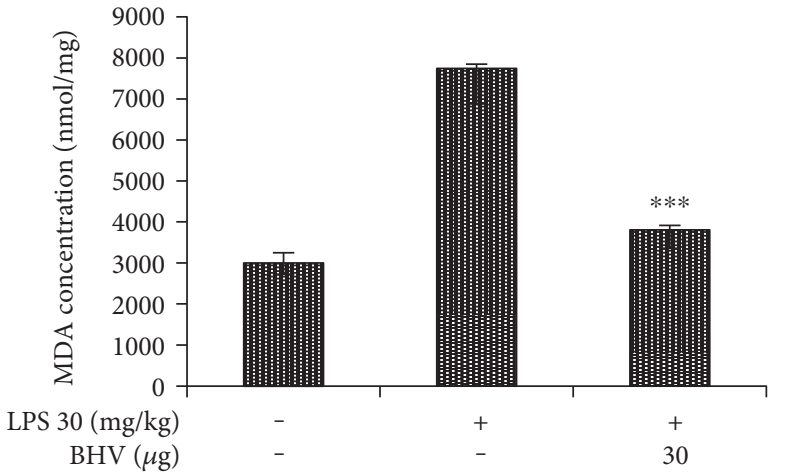

(a)

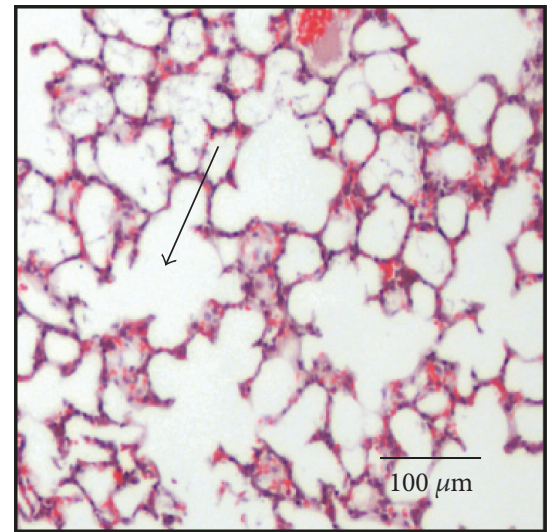

(c)

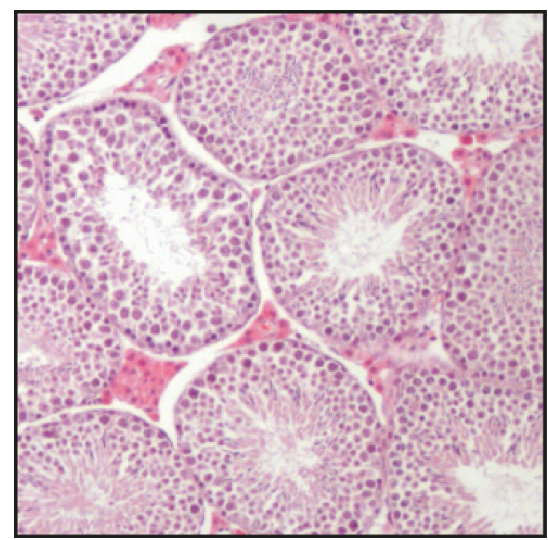

(f)

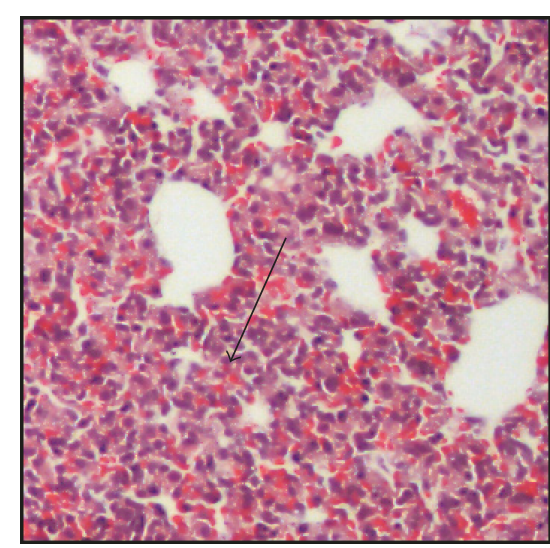

(d)

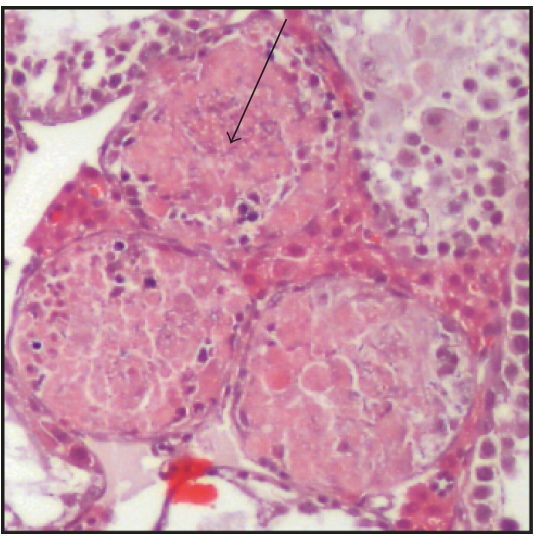

(g)

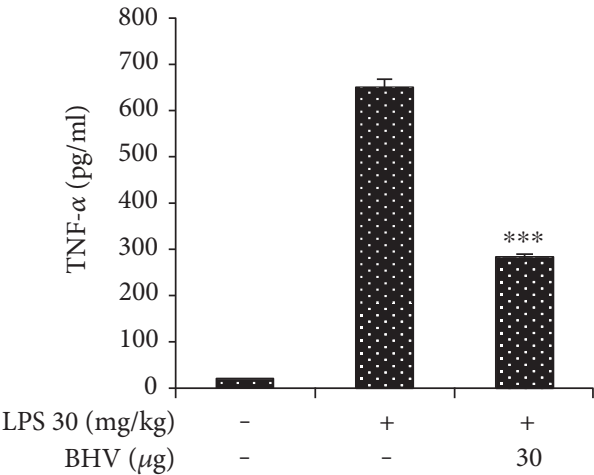

(b)

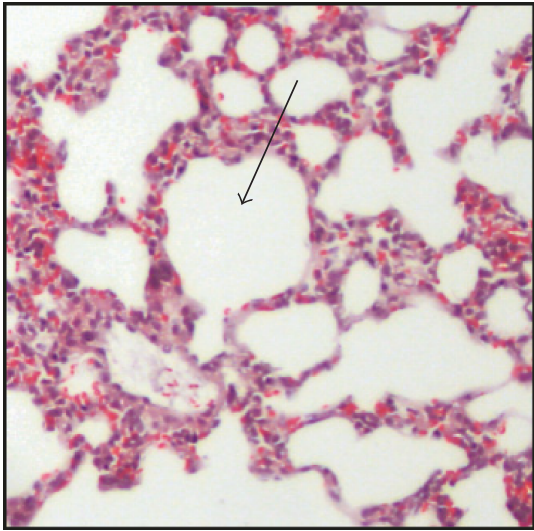

(e)

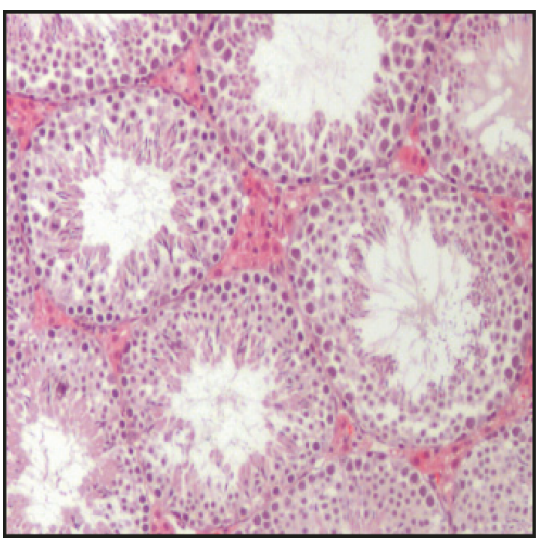

(h)

Figure 4: Reduction of serum TNF- $\alpha$ and MDA levels by BHV. For the chronic study of septic shock in mice by LPS, mice were treated with venom for 5 days and then were given the LPS injection. 3 days later, they were euthanized and blood and tissues were collected for TNF- $\alpha$ and MDA levels by commercially available kits. TNF- $\alpha$ levels (a) and MDA levels (b). Values in bar graphs are mean \pm SEM of three independent experiments. ${ }^{* * *} p<0.001$ is considered significant compared to LPS group only. For hematoxylin and eosin staining, lung and testis tissues were stored in $10 \%$ neutral buffered formalin (NBF) and then stained according to standardized protocol for (H\&E) staining. Lungs (c-e) and testis (f-h). Scale bar $100 \mu \mathrm{m}$.

paralyzing their host for long or short terms, which interrupts with their developmental or immune processes [12, 18-22]. Previously, many studies had always been limited to the host-parasite relationship studies especially in the context of agricultural pests. This could be attributed to the fact that venoms either from arthropods or reptiles are considered to be dangerously toxic and are severe inflammation- inducing agents. Bee venom however in this regard can be considered as a novel extract that has been studied extensively for its outstanding anti-inflammatory, anti-tumorous, and immune boosting properties [23-26]. Keeping this in mind and also the fact that hymenopteran venoms consist of numerous antimicrobial peptides that can be easily injected in the mammalian subjects to serve as antibiotics, 


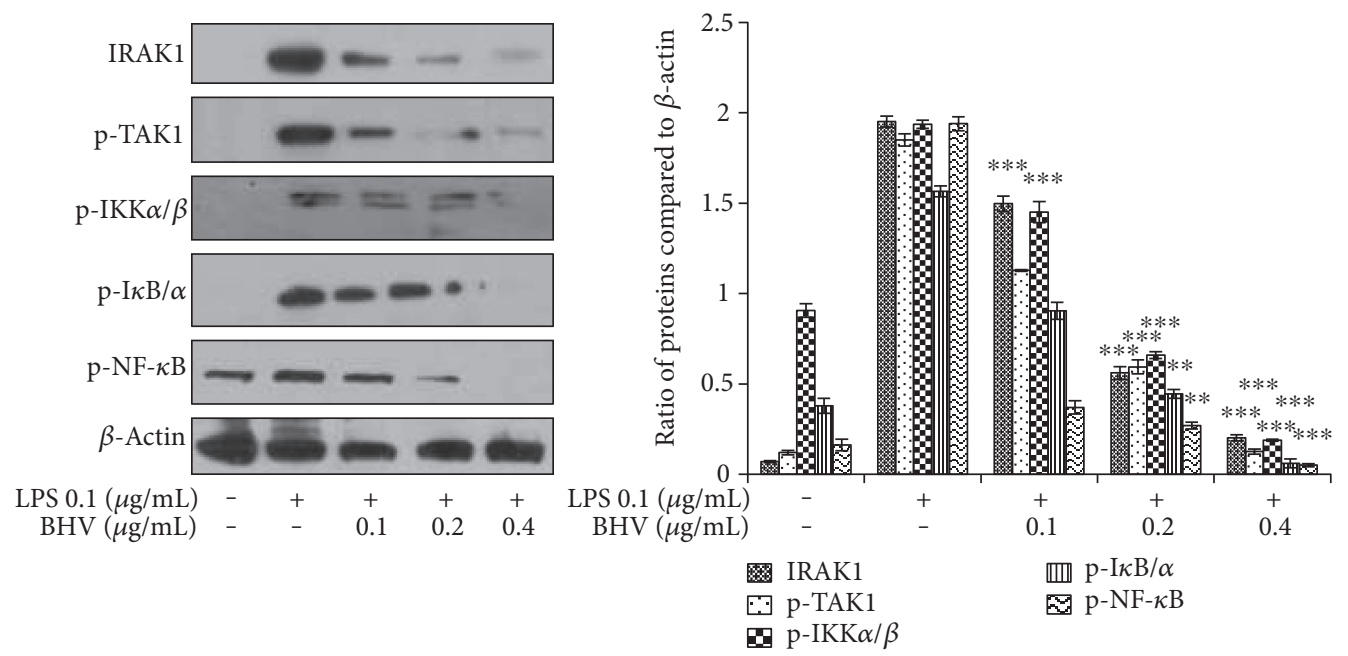

(a)
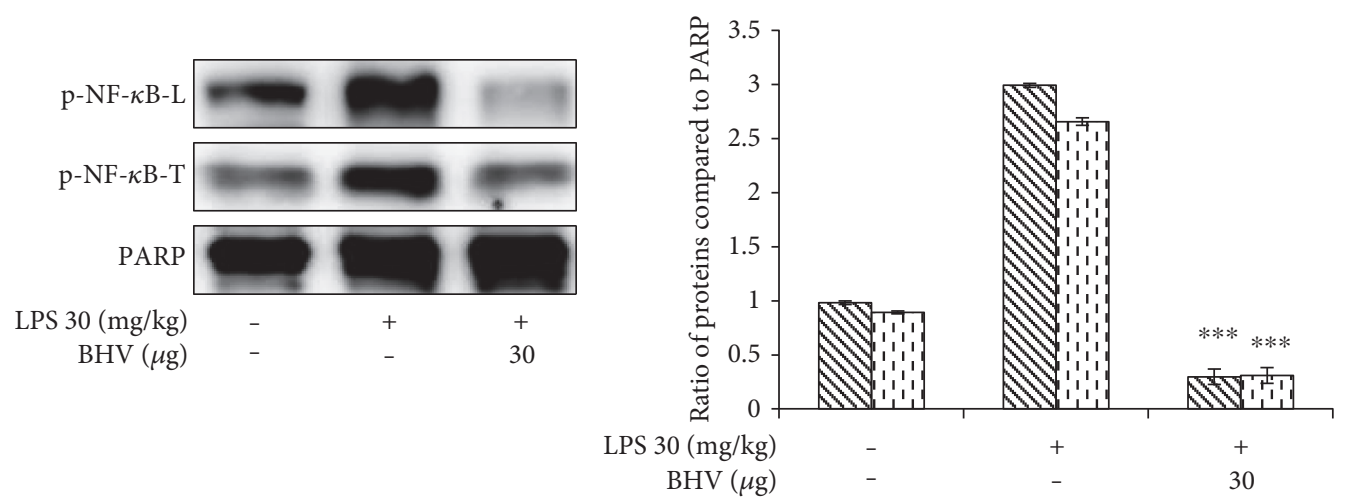

N p-NF- $\kappa$ B-lung

[i. $\mathrm{i}$-NF- $\kappa \mathrm{B}$-testis

(b)
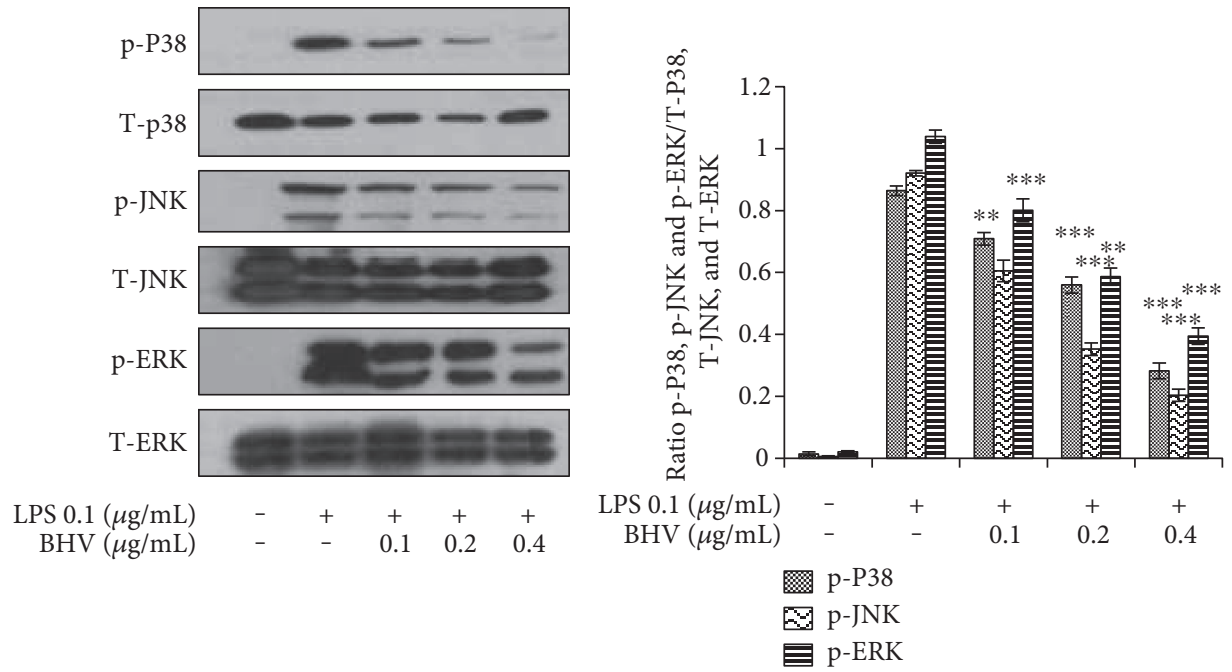

(c)

FIGURE 5: NF- $\kappa$ B and MAPK pathways are followed by B. hebetor venom. RAW 264.7 cells were pretreated with BHV at the indicated concentrations $(0.1 \mu \mathrm{g} / \mathrm{mL}-0.4 \mu \mathrm{g} / \mathrm{mL})$ and then stimulated with or without LPS $(0.1 \mu \mathrm{g} / \mathrm{mL})$ for 18 hr. Nuclear and cytosolic proteins from cells and tissues were extracted using NE-PER extraction kit. Proteins were run on SDS-PAGE and treated with primary antibodies overnight followed by incubation with secondary antibodies for $2 \mathrm{hr}$. Expression of proteins in cells (a). Expression of proteins in lung and testis tissue (b). MAPK pathway proteins expression (c). The membranes were analyzed by ECL chemiluminescence system. Data are mean \pm SD $(n=3) ;{ }^{* *} p<0.005$ and ${ }^{* * *} p<0.001$ compared with LPS only. $\beta$-actin was taken as internal control. 

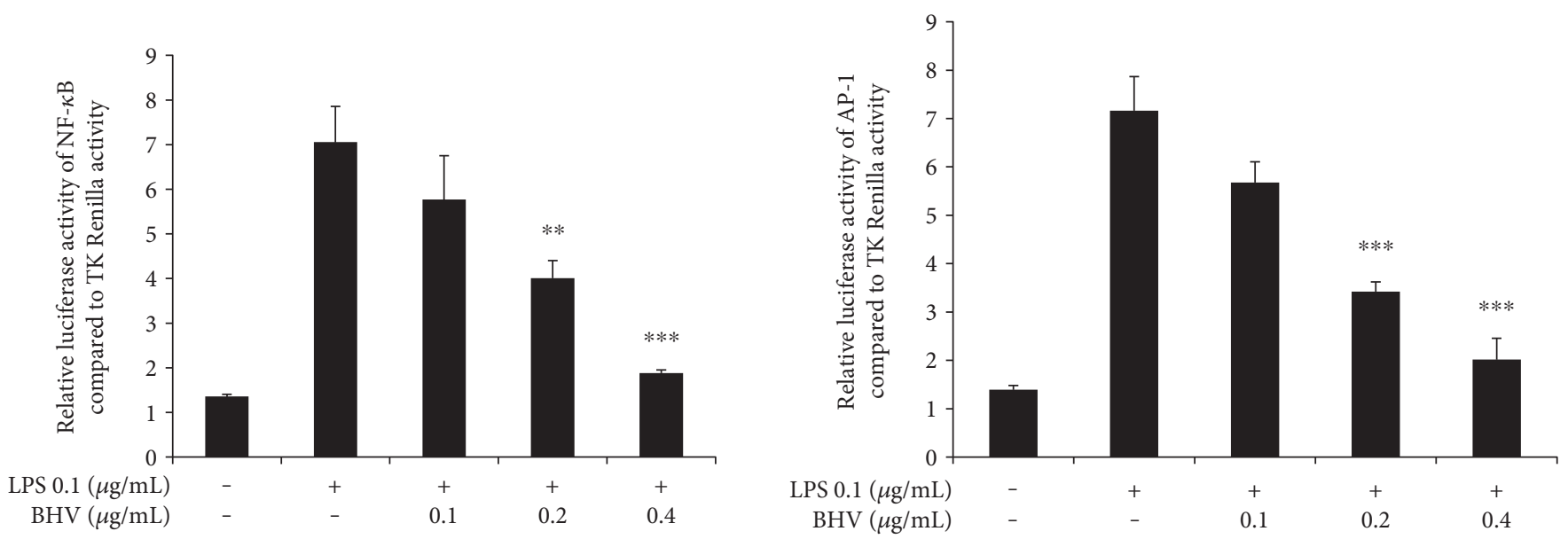

Figure 6: Effects of $B$. hebetor venom on NF- $\kappa$ B and AP-1 transcriptional activities. HEK 293T cells were cultured in 24-well plates and after $18 \mathrm{hr}$ of incubation were transfected with NF- $\kappa \mathrm{B}, \mathrm{AP}-1$, and TK Renilla plasmids using the calcium-phosphate method. 48 hr after transfection, cells were pretreated with indicated concentrations of BHV $(0.1 \mu \mathrm{g} / \mathrm{mL}-0.4 \mu \mathrm{g} / \mathrm{mL})$ and then stimulated with PMA $(0.1 \mu \mathrm{M})$ for $6 \mathrm{hr}$. Luciferase activity was later measured using Dual-Glo luciferase assay system. NF- $\kappa$ B and AP-1 activity was normalized to TK Renilla activity and concentrations were compared to PMA Renilla luciferase activity. Bar graph is mean \pm SEM of triplicates. ${ }^{* * *} p<0.001$ and ${ }^{* *} p<0.005$ were considered statistically significant.

we geared to check the anti-inflammatory activities of BHV [27-29]. Some studies in the past had also investigated the antinociceptive effects of these venom proteins that cause the occlusion of ion channels thus reducing the pain threshold $[30,31]$.

Different kinds of proteins are present in the composition of any kind of venom. Protein profiles for B. hebetor venom showed that it consists of three major amino acids with their molecular weight ranging around $73 \mathrm{KDa}$. Previously, we have investigated the biological control of IMM via $B$. hebetor on the transcriptional level of genes that are involved in the immunity, metabolism, and development of this pest. However, in regard to the venom itself, we conducted our study to check its anti-inflammatory effects on mammalian cells at very low dosages [12].

Our results indicate that $\mathrm{BHV}$ has inhibited the NO production in a dose-dependent manner without any cytotoxicity for our dosage range. $\mathrm{NO}$ is a natural defensive gaseous chemical that is produced in response to the foreign invasion in the body or cells. During the combat between foreign particles and cells, their levels are always upregulated which show the first sign of inflammatory reaction in the body. Although its production is good for the rapid neutralization of foreign invader, yet if uncontrolled, it starts destroying the neighboring healthy cells [32].

Proinflammatory mediators are those genes that are responsible for the downstream signaling for activation of inflammatory pathways. Among them, the two most commonly encountered mediators are iNOS and COX-2. In our results, BHV has potently inhibited the expression levels of both of these mediators both at the transcriptional and translational levels indicating that BHV has the potency to inhibit the expression of agents causing inflammation.

After proinflammatory mediators, proinflammatory cytokines come into the play. These are the chemicals responsible for causing the local or systemic inflammation depending upon their timely control and levels of a foreign invader. The first three proinflammatory cytokines are mustered out, the IL- $1 \beta$, IL- 6 , and TNF- $\alpha$ [33]. The release of these proinflammatory cytokines serves to flare-up the inflammatory process that is being suppressed by BHV in our results. Timely control through an endogenous or exogenous agent is critical to control these chemicals as it can lead to systemic infection in no time [34].

We have discussed the release of NO, proinflammatory mediators, and cytokines previously, but there are some pathways that cause the production of these agents from an extracellular to intracellular environment. Nuclear factor kappa B pathway (NF- $\kappa \mathrm{B}$ ) is one of the classical inflammatory pathways that is activated whenever there is some foreign invasion in the cell. This pathway comprises a series of transcriptional components from the cytoplasm and nucleus that is responsible for the induction of inflammation. NF- $\kappa B$ signaling initiates the stimulation of IRAK1 that phosphorylates TAK1 which acts upon IKK $\alpha / \beta$ that is present at dormancy in the cytoplasm. Activated phosphorylation of IKK $\alpha / \beta$ stimulates $\mathrm{I} \kappa \mathrm{B} \alpha$ subunit of NF- $\kappa \mathrm{B}$ setting it free to translocate into the nucleus [35-37]. In our results, BHV has dose dependently suppressed the phosphorylation expression of every component related to classical NF- $\kappa \mathrm{B}$ and MAPK pathways.

\section{Conclusion}

In conclusion, BHV has inhibited the phosphorylation of all factors involved in both of the above-stated pathways both in vitro and in vivo. Therefore, BHV can be reckoned as a strong anti-inflammatory agent in future for advanced molecular studies. 


\author{
Abbreviations \\ BHV: $\quad$ B. hebetor venom \\ IMM: Indianmeal moth \\ LPS: $\quad$ Lipopolysaccharides \\ NO: $\quad$ Nitric oxide \\ iNOS: Inducible NO synthase \\ TNF- $\alpha$ : Tumor necrotic factor alpha \\ COX-2: Cyclooxygenase-2 \\ NF- $\kappa$ B: Nuclear factor kappa B \\ MAPK: Mitogen-activated protein kinases \\ TLR: Toll-like receptors \\ IL: Interleukin \\ ERK: Extracellular signal-regulated kinases \\ JNK: c-Jun N-terminal kinases \\ IKK: Inhibitor of kappa B kinase \\ $\mathrm{I} \kappa \mathrm{B} / \alpha$ : Inhibitor kappa B-alpha.
}

\section{Conflicts of Interest}

All the authors have declared no competing interests.

\section{Acknowledgments}

This research was supported by the National Research Foundation of Korea grant funded by the Korean Government (no. 2015R1D1A1A09057204).

\section{References}

[1] H. Faal-Mohammad-Ali and P. Shishehbor, "Biological parameters of Bracon Hebetor (Hym.: Braconidae) parasitizing Ephestia kuehniella (Lep.: Pyralidae): effect of host diet," Journal of Crop Protection, vol. 2, no. 4, pp. 411-419, 2013.

[2] T. J. Alves, C. S. Silva-Torres, V. Wanderley-Teixeira et al., "Behavioral studies of the parasitoid Bracon vulgaris Ashmead (hymenoptera: Braconidae)," Journal of Insect Behavior, vol. 28, no. 5, pp. 604-617, 2015.

[3] M. N. Ghimire and T. W. Phillips, "Suitability of different lepidopteran host species for development of Bracon hebetor (Hymenoptera: Braconidae)," Environmental Entomology, vol. 39, no. 2, pp. 449-458, 2010.

[4] G. N. Mbata and D. I. Shapiro-Ilan, "Compatibility of Heterorhabditis indica (Rhabditida: Heterorhabditidae) and Habrobracon hebetor (hymenoptera: Braconidae) for biological control of Plodia interpunctella (Lepidoptera: Pyralidae)," Biological Control, vol. 54, no. 2, pp. 75-82, 2010.

[5] E. J. Im, S. J. Kim, S. B. Hong, J. K. Park, and M. H. Rhee, "Anti-inflammatory activity of bee venom in BV2 microglial cells: mediation of MyD88-dependent NF- $\kappa \mathrm{B}$ signaling pathway," Evidence-based Complementary and Alternative Medicine, vol. 2016, Article ID 3704764, 11 pages, 2016.

[6] H. J. An, W. R. Lee, K. H. Kim et al., "Inhibitory effects of bee venom on Propionibacterium acnes-induced inflammatory skin disease in an animal model," International Journal of Molecular Medicine, vol. 34, no. 5, pp. 1341-1348, 2014.

[7] S. M. Han, K. G. Lee, and S. C. Pak, "Effects of cosmetics containing purified honeybee (Apis mellifera L.) venom on acne vulgaris," Journal of Integrative Medicine, vol. 11, no. 5, pp. 320-326, 2013.
[8] R. Medzhitov, "Origin and physiological roles of inflammation," Nature, vol. 454, no. 7203, pp. 428-435, 2008.

[9] C. A. Dinarello, "Proinflammatory cytokines," Chest, vol. 118, no. 2, pp. 503-508, 2000.

[10] W. Zhang and H. T. Liu, "MAPK signal pathways in the regulation of cell proliferation in mammalian cells," Cell Research, vol. 12, no. 1, pp. 9-18, 2002.

[11] G. B. Quistad, Q. Nguyen, P. Bernasconi, and D. J. Leisy, "Purification and characterization of insecticidal toxins from venom glands of the parasitic wasp, Bracon hebetor," Insect Biochemistry and Molecular Biology, vol. 24, no. 10, pp. 955961, 1994.

[12] S. J. Moreau and S. Asgari, "Venom proteins from parasitoid wasps and their biological functions," Toxins, vol. 7, no. 7, pp. 2385-2412, 2015.

[13] E. Saba, Y. Son, B. R. Jeon et al., “Acetyl Eburicoic acid from Laetiporus sulphureus var. miniatus suppresses inflammation in murine macrophage RAW 264.7 cells," Mycobiology, vol. 43, no. 2, pp. 131-136, 2015.

[14] E. Saba, B. R. Jeon, D. H. Jeong et al., “A novel Korean red ginseng compound gintonin inhibited inflammation by MAPK and NF- $\kappa$ B pathways and recovered the levels of mir-34a and mir-93 in RAW 264.7 cells," Evidence-based Complementary and Alternative Medicine, vol. 2015, Article ID 624132, 11 pages, 2015.

[15] A. H. Fischer, K. A. Jacobson, J. Rose, and R. Zeller, "Hematoxylin and eosin staining of tissue and cell sections," Cold Spring Harbor Protocols, vol. 2008, no. 6, 2008, pdb. prot4986.

[16] C. Alexander and E. T. Rietschel, "Bacterial lipopolysaccharides and innate immunity," Journal of Endotoxin Research, vol. 7, no. 3, pp. 167-202, 2001.

[17] T. Lawrence, "The nuclear factor NF- $\kappa$ B pathway in inflammation," Cold Spring Harbor Perspectives in Biology, vol. 1, no. 6, article a001651, 2009.

[18] N. M. Dheilly, F. Maure, M. Ravallec et al., "Who is the puppet master? Replication of a parasitic wasp-associated virus correlates with host behaviour manipulation," Proceedings Biological Sciences/The Royal Society, vol. 282, no. 1803, article 20142773, 2015.

[19] J. P. Edwards, H. A. Bell, N. Audsley et al., "The ectoparasitic wasp Eulophus pennicornis (Hymenoptera: Eulophidae) uses instar-specific endocrine disruption strategies to suppress the development of its host Lacanobia oleracea (Lepidoptera: Noctuidae)," Journal of Insect Physiology, vol. 52, no. 11-12, pp. 1153-1162, 2006.

[20] N. A. Kryukova, I. M. Dubovskiy, E. A. Chertkova, Y. L. Vorontsova, I. A. Slepneva, and V. V. Glupov, "The effect of Habrobracon hebetor venom on the activity of the prophenoloxidase system, the generation of reactive oxygen species and encapsulation in the haemolymph of Galleria mellonella larvae," Journal of Insect Physiology, vol. 57, no. 6, pp. 796-800, 2011.

[21] F. Pennacchio and M. R. Strand, "Evolution of developmental strategies in parasitic hymenoptera," Annual Review of Entomology, vol. 51, pp. 233-258, 2006.

[22] C. Tian, L. Wang, G. Ye, and S. Zhu, "Inhibition of melanization by a Nasonia defensin-like peptide: implications for host immune suppression," Journal of Insect Physiology, vol. 56, no. 12, pp. 1857-1862, 2010.

[23] S. S. Nipate, P. B. Hurali, and M. M. Ghaisas, "Evaluation of anti-inflammatory, anti-nociceptive, and anti-arthritic 
activities of Indian Apis dorsata bee venom in experimental animals: biochemical, histological, and radiological assessment," Immunopharmacology and Immunotoxicology, vol. 37, no. 2, pp. 171-184, 2015.

[24] S. W. Seo, W. S. Jung, S. E. Lee et al., "Effects of bee venom on cholecystokinin octapeptide-induced acute pancreatitis in rats," Pancreas, vol. 36, no. 2, pp. e22-e29, 2008.

[25] H. L. Lee, S. H. Park, T. M. Kim et al., "Bee venom inhibits growth of human cervical tumors in mice," Oncotarget, vol. 6, no. 9, pp. 7280-7292, 2015.

[26] C. C. Liu, D. J. Hao, Q. Zhang et al., "Application of bee venom and its main constituent melittin for cancer treatment," Cancer Chemotherapy and Pharmacology, vol. 78, no. 6, pp. 1113-1130, 2016.

[27] L. Kuhn-Nentwig, "Antimicrobial and cytolytic peptides of venomous arthropods," Cellular and Molecular Life Sciences: CMLS, vol. 60, no. 12, pp. 2651-2668, 2003.

[28] X. Shen, G. Ye, X. Cheng, C. Yu, H. Yao, and C. Hu, "Novel antimicrobial peptides identified from an endoparasitic wasp cDNA library," Journal of Peptide Science, vol. 16, no. 1, pp. 58-64, 2010.

[29] J.-Y. Zhu, G.-Y. Ye, and C. Hu, "Venom of the endoparasitoid wasp Pteromalus puparum: an overview," Psyche, vol. 2011, Article ID 520926, 7 pages, 2011.

[30] A. T. Eldefrawi, M. E. Eldefrawi, K. Konno et al., "Structure and synthesis of a potent glutamate receptor antagonist in wasp venom," Proceedings of the National Academy of Sciences of the United States of America, vol. 85, no. 13, pp. 4910-4913, 1988.

[31] T. Piek, " $\delta$-philanthotoxin, a semi-irreversible blocker of ion-channels," Comparative Biochemistry and Physiology C: Comparative Pharmacology, vol. 72, no. 2, pp. 311-315, 1982.

[32] C. Bogdan, "Nitric oxide and the immune response," Nature Immunology, vol. 2, no. 10, pp. 907-916, 2001.

[33] J.-M. Zhang and J. An, "Cytokines, inflammation and pain," International Anesthesiology Clinics, vol. 45, no. 2, p. 27, 2007.

[34] P. Wojdasiewicz, L. A. Poniatowski, and D. Szukiewicz, "The role of inflammatory and anti-inflammatory cytokines in the pathogenesis of osteoarthritis," Mediators of Inflammation, vol. 2014, Article ID 561459, 19 pages, 2014.

[35] Q. Li and I. M. Verma, "NF- $\kappa$ B regulation in the immune system," Nature Reviews Immunology, vol. 2, no. 10, pp. 725734, 2002.

[36] P. P. Tak and G. S. Firestein, "NF- $\kappa$ B: a key role in inflammatory diseases," The Journal of Clinical Investigation, vol. 107, no. 1, pp. 7-11, 2001.

[37] P. Viatour, M.-P. Merville, V. Bours, and A. Chariot, "Phosphorylation of $\mathrm{NF}-\kappa \mathrm{B}$ and $\mathrm{I} \kappa \mathrm{B}$ proteins: implications in cancer and inflammation," Trends in Biochemical Sciences, vol. 30, no. 1, pp. 43-52, 2005. 


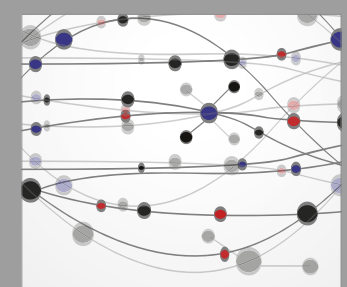

The Scientific World Journal
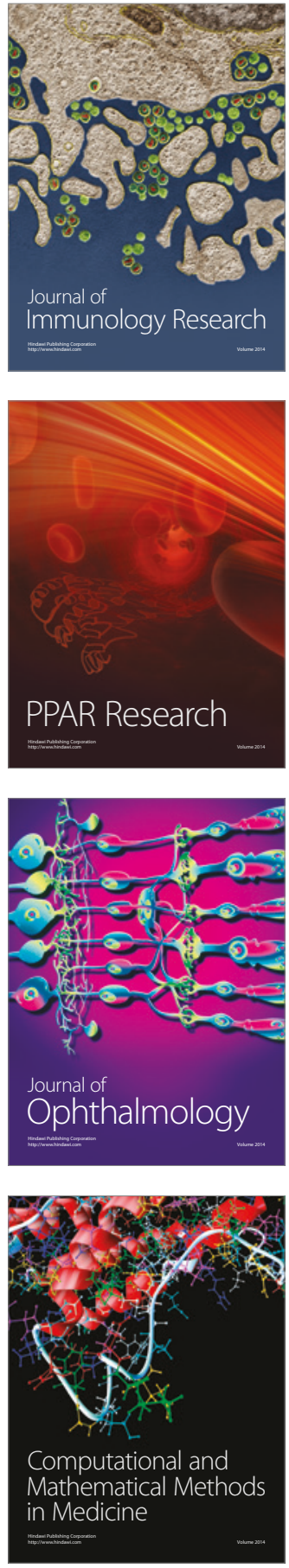

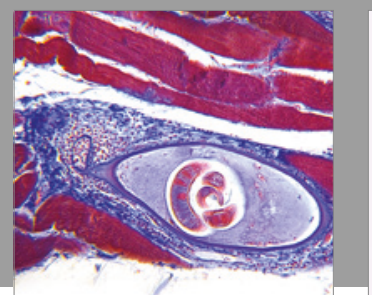

Gastroenterology Research and Practice
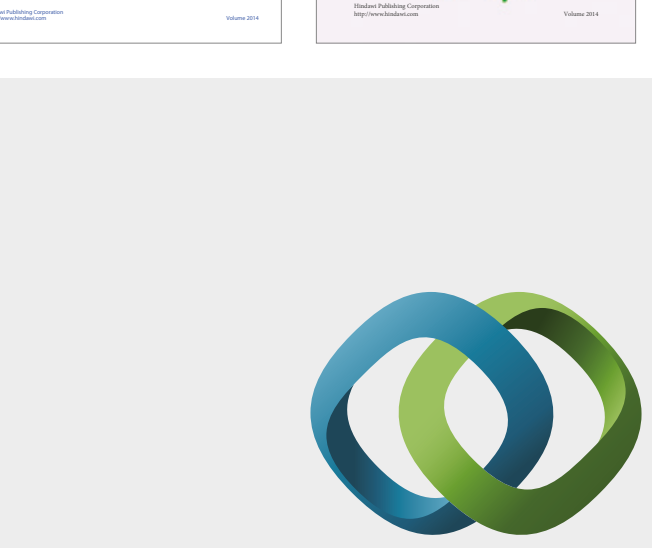

\section{Hindawi}

Submit your manuscripts at

https://www.hindawi.com
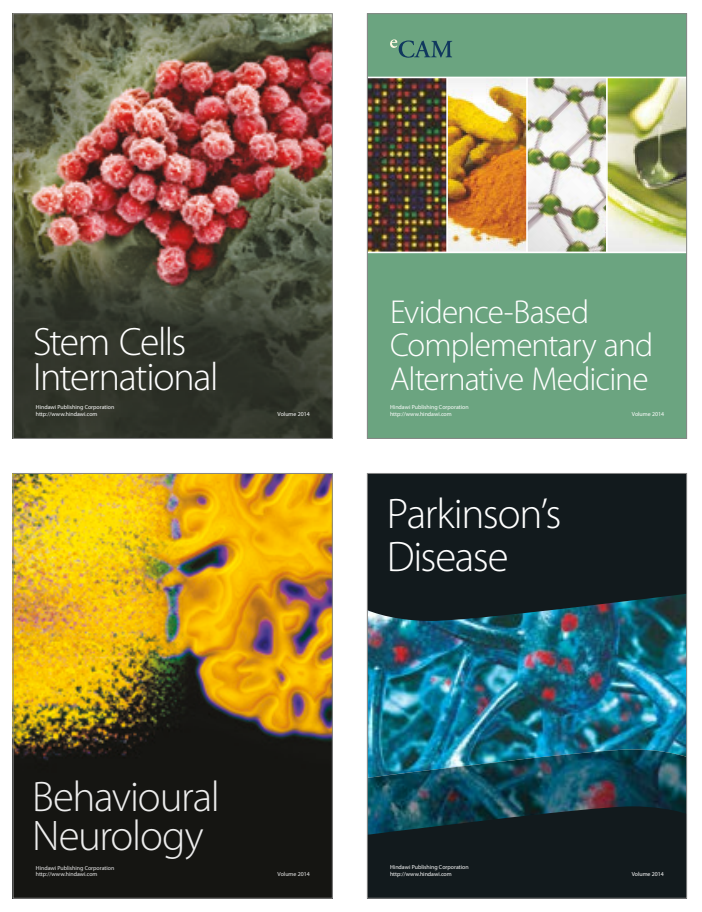
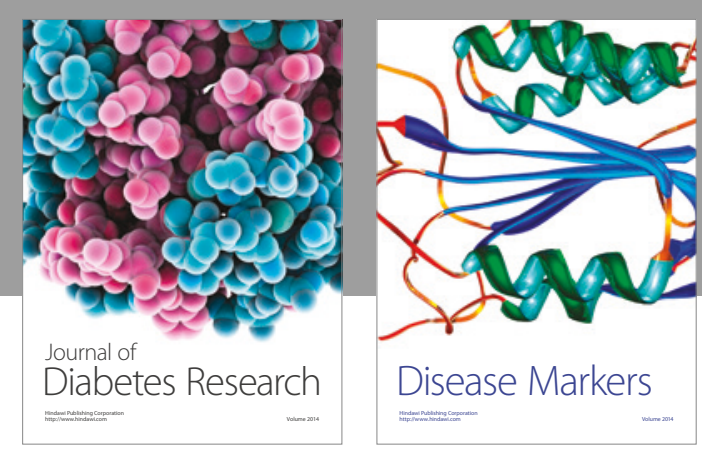

Disease Markers
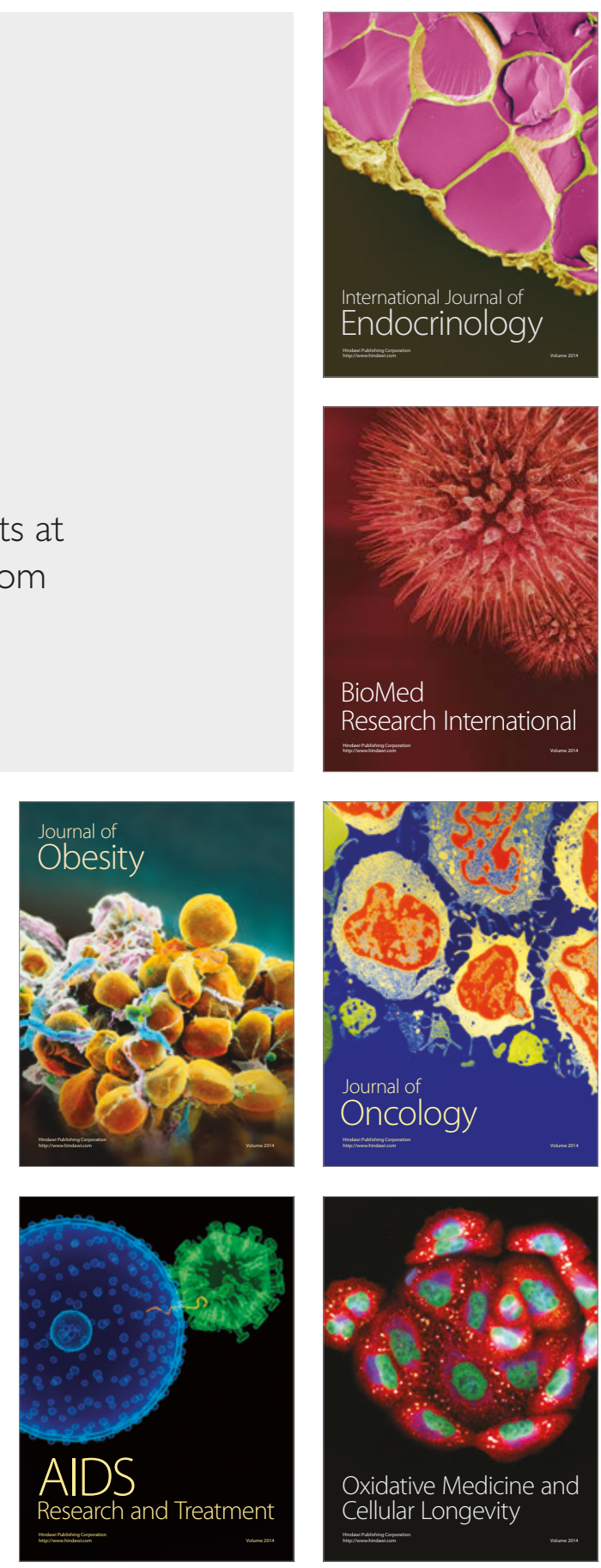